Режим доступа: http://www.garant.ru/products/ipo/ prime/doc/56599536.

6. Хасаншин И.А. Закономерность и тенденции развития инновационного предпринимательства. - Режим доступа: https://elibrary.ru/download/ elibrary_27523115_65690743.pdf.

Воротников Игорь Леонидович, д- $p$ экон. наук, проф., зав. кафедрой «Организация производства и управление бизнесом в АПК», Саратовский государственный аграрный университет имени Н.И. Вавилова. Россия.
Нейфельд Василий Вольдемарович, канд. геогр. наук, доиент кафедры «Землеустройство и кадастры», Саратовский государственный аграрный университет имени Н.И. Вавилова. Россия.

410012, г. Саратов, Театральная пл., 1.

Тел.: (8452)26-27-83.

Ключевые слова: ицировые технологии; земельные ресурсы; агропромышленный комплекс; управление; экономическая эффективность.

\title{
THE EFFICACY OF DIGITAL TECHNOLOGY IN LAND ADMINISTRATION OF MUNICIPALITIES OF THE SARATOV REGION
}

Vorotnikov Igor Leonidovich, Doctor of Economic Sciences, Professor, Head of the chair "Organization of Production and Business Management in AIC”, Saratov State Agrarian University named after N.I. Vavilov. Russia

Neyfeld Vasily Voldemarovich, Candidate of Geographical Sciences, Associate Professor of the Chair "Land Management and Cadaster", Saratov State Agrarian University named after N.I. Vavilov. Russia.

Keywords: digital technologies; land resources; agro-industrial complex; management; economic efficiency.
The need to manage land resources in the emerging socio-economic conditions requires a wide application of geoinformation systems in creating a single information field, including for the agricultural sector. The wide introduction of digital technologies into the management of the agro-industrial complex will improve the quality of management of the industry at macro and micro levels, increase the overall profitability of agricultural production and, in the end, improve the investment attractiveness of the industry. The article examines the experience of introducing digital technologies in the management of land resources in the right-bank districts of the Saratov region.

\section{МОДЕЛЬ ПОВЫШЕНИЯ ЭФФЕКТИВНОСТИ СЕЛЬСКОХОЗЯЙСТВЕННОГО ЗЕМЛЕПОЛЬЗОВАНИЯ}

удк 332.3

\author{
ЗАВОРОТИН Евгений Феофанович, Поволжский научно-исследовательский институт \\ экономики и организации агропромышленного комплекса
}

ГОРдОПОЛОВА Алла Александровна, Поволжский научно-исследовательский институт экономики и организации агропромышленного комплекса

ТЮРИНА Наталья Сергеевна, Поволжский научно-исследовательский институт экономики и организации агропромышленного комплекса

ПОТОЦКАЯ Людмила Николаевна, Поволжский научно-исследовательский институт экономики и организации агропромышленного комплекса

\begin{abstract}
Предложена процессная модель регулирования взаимодействия участников земельных отношений посредством обеспечения функиионирования метода повышения эффективности сельскохозяйственного землепользования. Определены виды издержек, имеющие наибольшую значимость для повышения эффективности сельскохозяйственного землепользования. Рассмотрены направления минимизации земельных платежей, денежных взысканий, затрат на агротехнические мероприятия по сохранению, восстановлению плодородия почв, предотвращению их деградации, а также монокультурного возделывания. Выявлены особенности осуществления платежей сельскохозяйственными товаропроизводителями за нанесение ущерба окружающей среде, возможности компенсации им расходов на улучшение малопродуктивных земель. Обоснован комплекс мероприятий, направленных на полное или частичное возмещение государством затрат по защите окружающей природной среды, перераспределение сумм, поступающих в бюджет соответствующих платежей для поощрения землепользователей, соблюдающих нормы экологической безопасности. Проведена сравнительная оценка участников земельных отношений с позиций эффективного и неэффективного использования земель в сельском хозяйстве.
\end{abstract}

Введение. Рыночно-институциональная трансформация экономики агропромышленного комплекса не обеспечила должной эффективности использования земель в сельскохозяйственном про- изводстве $[1,5]$. По данным Федеральной службы государственной регистрации, кадастра и картографии, на 1 января 2016 г. площадь земель сельскохозяйственного назначения составила 383,7 млн га, 
сократившись по сравнению с предыдущим годом на 1,8 млн га. Доля земель сельскохозяйственного назначения в общей площади субъектов Российской Федерации варьируется от 1,2% (Республика Карелия) до 94,5 \% (Ненецкий автономный округ). Разрушению покрова, заболачиванию, засолению, опустыниванию подвержено более трети почв сельскохозяйственных угодий страны. В Приволжском федеральном округе основным процессом деградации являются эрозии, которыми охвачено свыше трех четвертей площади региона. Во многих областях и республиках, за исключением отдельных землепользований, они имеют тенденцию к усилению. Процессы водной эрозии максимально развиты в республиках Татарстан, Башкортостан и прогрессируют в Самарской, Саратовской, Волгоградской областях [12]. Заинтересованность в эффективном использовании земель сельскохозяйственного назначения свидетельствует о важности данной проблемы и вызывает необходимость его обеспечения посредством реализации предлагаемой процессной модели.

Цель исследования - построить модель для разработанного авторами метода оптимизации издержек с учетом мероприятий по уменьшению агроистощения почв.

Методика исследований. Авторский метод оптимизации издержек направлен на получение экономии в результате сокращения негативного воздействия эрозии, засоления почв, последствий бессменного возделывания коммерческих культур, полного или частичного возмещения государством затрат на проведение почвозащитных мероприятий и др.

Результаты исследований. Метод оптимизации издержек с учетом мероприятий по уменьшению агроистощения почв обеспечивает получение эффективности трех видов: экономической - за счет экономии, минимизации упущенной выгоды; экологической - ограничения деструктивных процессов, засоления и др., социальной - усиления ответственности за ненадлежащее использование сельскохозяйственных угодий.

Суть разработанного метода прослеживается по модели процесса его функционирования, эффект от сельскохозяйственного землепользования складывается из трех составляющих (см. рисунок).

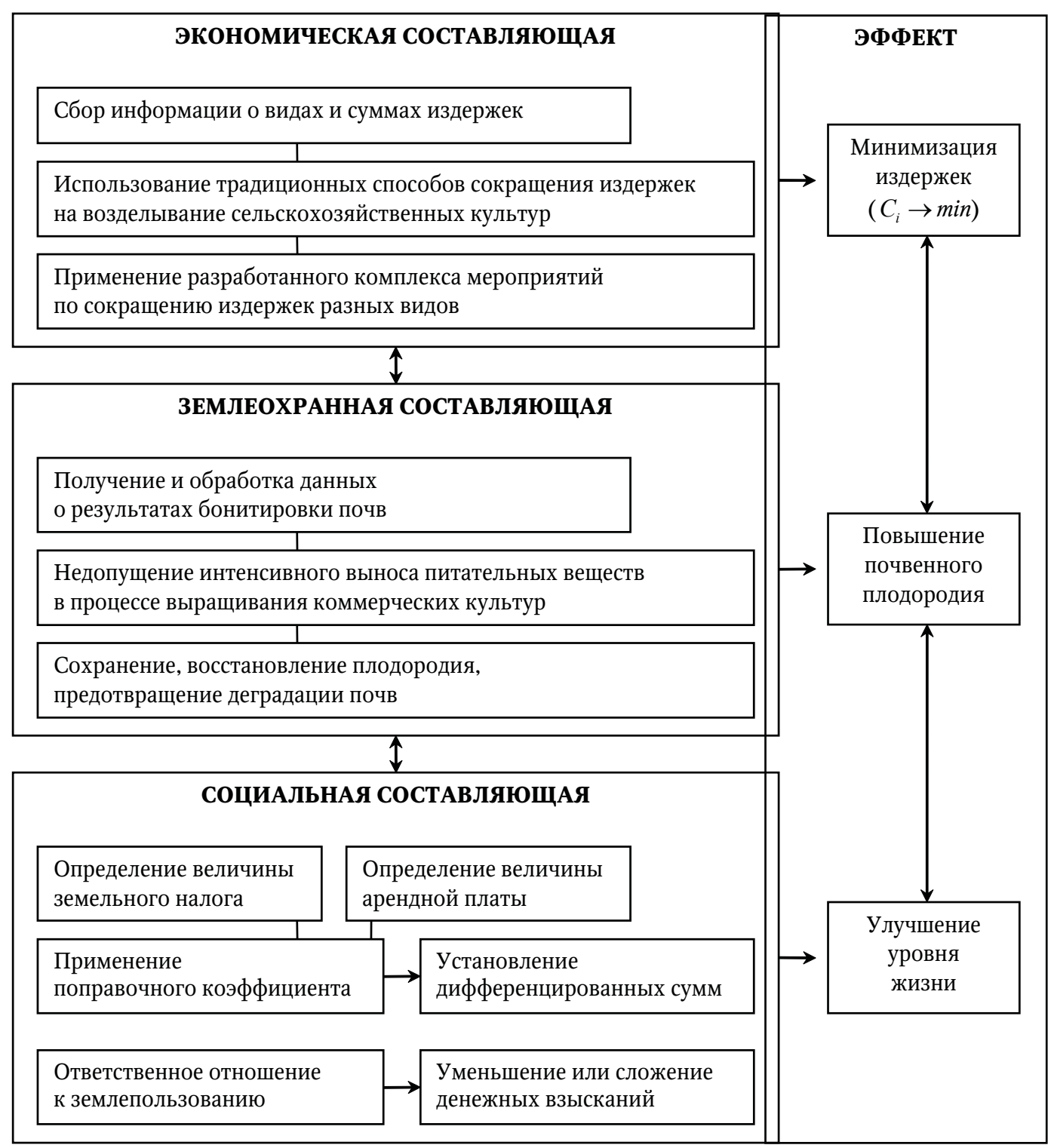

Процессная модель обеспечения функционирования метода повышения эффективности сельскохозяйственного землепользования 
Система описывается тремя согласованными этапами, включающими пошаговое выполнение предложенных действий в экономическом, землеохранном и социальном направлениях механизм повышения эффективности сельскохозяйственного землепользования. Каждый из них оказывает существенное влияние на процесс управления земельными ресурсами и в совокупности позволяет оптимизировать издержки разных видов, уменьшить разрушительное воздействие эрозии (дефляции) почв, не допускать отступлений от севооборотных требований, от рекомендаций научных учреждений зоны по размещению культур в севообороте, оказать положительное влияние на воспроизводство плодородных свойств земель, воспитать экологическое сознание и др. [2, 8].

Для достижения экономического эффекта наибольшую значимость имеют следующие издержки.

Издержки на возделывание сельскохозяйственных культур $C_{1}$ зависят от деятельности и взаимодействия участников земельных отношений и рассчитываются по формуле:

$$
C_{1}=C_{\mathrm{OT}}+C_{\mathrm{M \Pi} 3}+C_{\mathrm{A}}+C_{\mathrm{TOPX}}+C_{\Pi},
$$

где $C_{\text {от }}$ - затраты на оплату труда работников, руб./га; $C_{\text {мпз }}$ - затраты на приобретение материально-производственных запасов, руб./га; $C_{\mathrm{A}}-$ затраты на амортизацию, руб./га; $C_{\text {торх }}$ - затраты на техническое обслуживание, ремонт, хранение техники, руб./га; $C_{\text {п }}$ - прочие затраты, руб./га.

Одним из возможных направлений снижения $C_{1}$ является поддержка государством сельскохозяйственных товаропроизводителей. Соответствующей программой предусмотрено выделение средств на развитие отрасли растениеводства в Саратовской области в 2017 г. из федерального бюджета в размере 524908 тыс. руб., регионального бюджета - 27627 тыс. руб. [6].

Издержки упущенных возможностей от потери урожая с деградированных, зараженных, неплодородных земель, или вмененные затраты $C_{2}$, определяются по формуле:

$$
C_{2}=n \Pi,
$$

где $n$ - количество брошенных, неиспользуемых, непригодных для возделывания сельскохозяйственных культур земельных участков, шт.; П прибыль, руб./га.
Минимизации $C_{2}$ будет способствовать недопущение хозяйствами всех категорий Саратовской области отклонений от предлагаемых зональной системой земледелия типовых схем различных видов севооборотов $[9,11]$.

Земельные платежи в форме земельного налога и арендной платы за землю $C_{3}$ рассчитываются по формуле:

$$
\mathrm{C}_{3}=(\mathrm{H}+\mathrm{a}) \mathrm{K}_{1},
$$

где н - земельный налог, руб./га; а - арендная плата, руб./га; К - поправочный коэффициент, учитывающий долю площади, пригодной для возделывания сельскохозяйственных культур.

Базой для расчета суммы земельных платежей $C_{3}$ является кадастровая стоимость земельного участка без учета качества и состояния предоставляемых в пользование земель сельскохозяйственного назначения. Для определения суммы начисленного к уплате земельного налога она умножается на 0,3 \%, размера арендной платы - на соответствующую ставку и коэффициенты времени, инфляционных процессов. Данное обстоятельство вызывает необходимость применения обоснованного коэффициента $\mathrm{K}_{1}$, исключающего площади занимаемых коммуникациями и дорожными трассами, нарушенных и иных не вовлеченных в хозяйственный оборот земель из общей площади. Значения $\mathrm{K}_{1}$ находятся в диапазоне от 1,0 до 0,1.

Издержки на агротехнические мероприятия по сохранению, восстановлению плодородия почв, предотвращению их деградации, а также монокультурного возделывания $C_{4}$ определяются по формуле:

$$
C_{4}=C_{\mathrm{C}}+C_{\mathrm{B}}+C_{\text {пд }}+C_{\text {пм }},
$$

где $C_{\mathrm{C}}$ - затраты на мероприятия по сохранению плодородия почв, руб./га; $C_{\text {в }}$ - затраты на мероприятия по восстановлению плодородия почв, руб./га; $C_{\text {пд }}$ - затраты на мероприятия по предотвращению деградации почв, руб./га; $C_{\text {пм }}-$ затраты на мероприятия по устранению монокультурной специализации, руб./га.

Снижение $C_{4}$ обеспечивается за счет осуществления комплекса предлагаемых действий, поддерживаемых государством или выполняемых собственниками, землепользователями, землевладельцами, арендаторами самостоятельно, без его участия (табл. 1).

Таблица 1

Участие государства в проведении мероприятий по уменьшению агроистощения почв

\begin{tabular}{|l|c|c|}
\hline \multicolumn{1}{|c|}{ Обстоятельство } & Степень & Действие \\
\hline $\begin{array}{l}\text { Выполнение собственниками, землепользователями, землевладельцами, арендаторами } \\
\text { обязательных мероприятий по поддержанию и восстановлению нормального состояния земель }\end{array}$ & низкая & контроль \\
\hline $\begin{array}{l}\text { Размер обязательных затрат на улучшение качества земель не соответствует финансовым } \\
\text { возможностям сельскохозяйственных товаропроизводителей }\end{array}$ & средняя & $\begin{array}{l}\text { субсиди- } \\
\text { рование }\end{array}$ \\
\hline Полное исчерпание полезных свойств земель в ходе их нецелевого использования & высокая & изъятие \\
\hline
\end{tabular}


Содействие органов власти должно быть оговорено в соответствующей программе, их вмешательство может определяться посредством реализации нормативно-рентного подхода к установлению предельных земель [4].

К данной категории принято относить земли сельскохозяйственного назначения, имеющие нулевое или отрицательное значение ренты в следующих случаях:

антропогенного воздействия (бесконтрольного, неумеренного использования удобрений, пестицидов и др.), приводящего к деградации почвенного покрова;

установления платежей за землю, превышающих приносимый ею доход;

наделения землями, непригодными для рентабельного производства продукции растениеводства (подверженными эрозии, склоновыми, закустаренными, засоренными камнями, заболоченными, засоленными и др.) [3].

Денежные взыскания, зависящие от соблюдения земельного законодательства, использования земель по целевому назначению, степени нарушения плодородия почв $C_{5}$, рассчитываются по формуле:

$$
C_{5}=n \mathrm{Y},
$$

где $\mathrm{У}$ - штрафные санкции за нанесение ущерба почвенному плодородию, руб./га.

Действие штрафных санкций за нанесение ущерба почвенному плодородию $C_{5}$ должно быть справедливым по отношению к собственникам, землепользователям, землевладельцам, арендаторам, поэтому следует дифференцировать размеры денежных взысканий в соответствии с градацией субъектов и их поведением (табл. 2).

Неэффективные участники групп $A, B, D, F$ подвергаются наложению на них штрафов в полном объеме согласно действующему законодательству. Та же мера материального воздействия должна применяться к субъектам группы C, необоснованно увеличивающим антропогенную нагрузку на сельскохозяйственные угодья. В случае, если им достались земли, подвергнувшиеся склоновым, деградационным и другим природным процессам, входящие в данную группу, они вправе подать заявление о сложении или уменьшении штрафов. На эффективных участников группы $E$ наказания в виде штрафов распространяться не должны.

Эффект по каждому виду издержек Э $i$ выражается в годовой экономии:

$$
\exists i=\Delta C_{i} .
$$

Реализация мероприятий по уменьшению агроистощения почв требует существенных затрат [7]. В связи с этим экономический эффект возникает через некоторый срок, денежные потоки приводятся к периоду осуществления капитальных вложений по следующей формуле:

$$
Э \phi=\sum_{t=1}^{N} \ni_{4} \cdot \frac{1}{(1+E)^{t}}-\sum_{t=0}^{N} \mathrm{~K} \cdot \frac{1}{(1+E)^{t}},
$$

где Эф - экономический эффект; $Э_{4}$ - эффект, который складывается не только из экономии $\Delta C_{4}$, но и из дополнительной прибыли П, получаемой в результате реализации сельскохозяйственной продукции; $E$ - норма дисконта; $t$ - номер шага расчета с момента начала осуществления агротехнического мероприятия $(0,1, \ldots, N)$; K - капитальные вложения на проведение агротехнических мероприятий.

Экономическая эффективность $e_{i}$ является процентным соотношением полученной годовой экономии и издержек:

$$
e_{i}=\frac{\ni_{i}}{C_{i}} \cdot 100
$$

Сокращение издержек обеспечивается правильным сочетанием предлагаемых способов воздействия.

Заключение. Построенная модель описывает реализацию предложенного метода оптимизации издержек с учетом мероприятий по охране почв от истощения посредством применения агротехнических, фискальных, экономических, правовых

Таблица 2

Характеристика групп эффективных и неэффективных участников земельных отношений

\begin{tabular}{|c|l|c|c|}
\hline \multirow{2}{*}{ Группа } & \multicolumn{1}{|c|}{ Содержание } & \multicolumn{2}{|c|}{ Участник земельных отношений } \\
\cline { 3 - 4 } & & $\begin{array}{c}\text { с позиции эффективного } \\
\text { сельскохозяйственного } \\
\text { землепользования }\end{array}$ & $\begin{array}{c}\text { с позиции неэффективного } \\
\text { сельскохозяйственного } \\
\text { землепользования }\end{array}$ \\
\hline$A$ & Не использующие земли & - & + \\
\hline$B$ & Использующие земли не по целевому назначению & + \\
\hline$C$ & $\begin{array}{l}\text { Использующие земли в сельскохозяйственном } \\
\text { производстве }\end{array}$ & + \\
\hline$D$ & $\begin{array}{l}\text { Нерационально использующие земли } \\
\text { в сельскохозяйственном производстве }\end{array}$ & + \\
\hline$E$ & $\begin{array}{l}\text { Использующие земли в сельскохозяйственном } \\
\text { производстве с проведением восстановительных } \\
\text { мероприятий }\end{array}$ & + \\
\hline$F$ & Нарушающие земли & + & + \\
\hline
\end{tabular}


и других способов повышения эффективности сельскохозяйственного землепользования. Выделены пять групп издержек, сокращение которых создает необходимые предпосылки для рациональной деятельности сельскохозяйственных товаропроизводителей. Выявлены способы минимизации затрат $C_{1}-C_{5}$, разграничения ответственности за выполнение обязательных мероприятий на основе нормативно-рентного подхода, введен поправочный коэффициент для определения сумм земельных платежей, проведена группировка участников земельных отношений с позиции эффективного и неэффективного сельскохозяйственного землепользования. Формализованы экономический эффект, в том числе с учетом дисконтирования разновременных денежных потоков, и экономическая эффективность.

\section{СПИСОК ЛИТЕРАТУРЫ}

1. Варламов А.А. Трансформация земельных отношений в России // Экономика сельскохозяйственных и перерабатывающих предприятий. - 2010. - № 9. C. 60-62.

2. Варламов А.А., Гальченко С.А., Клюшин П.В. Организационно-экономический механизм восстановления деградированных почв. - М.: Издательство ФГБОУ ВПО ГУЗ, 2013. - 236 с.

3. Заворотин Е.Ф. Регулирование земельных отношений: теория, методология, практика. - Саратов: ИЦ «Наука», 2006. - 215 с.

4. Заворотин Е.Ф., Гордополова А.А. Механизмы государственного регулирования земельных отношений в Поволжье // Научное обозрение. - 2015. № 11. - С. 305-307.

5. Заворотин Е.Ф., Гордополова А.А., Тюрина Н.С., Потоцкая Л.Н. Модель концептуально-методологических направлений трансформации земельных отношений // Фундаментальные исследования. 2017. - № 9. - С. 423-427.

6. Информационный справочник о мерах и направлениях государственной поддержки агропромышленного комплекса Российской Федерации. - Режим доступа: http://www.gp.specagro.ru/region/4969/2/22/6/2017.
7. Потоикая Л.Н. Некоторые аспекты оптимизации инвестиций в агрохимическое обслуживание // Научное обозрение. - 2013. - № 6. C. $211-216$.

8. Проблемы деградации и восстановления продуктивности земель сельскохозяйственного назначения в России / под ред. А.В. Гордеева, Г.А. Романенко. М.: ФГНУ «Росинформагротех», 2008. - 68 с.

9. Справочник экономиста аграрного производства / под общ. ред. А.А. Черняева. - Саратов: Приволжское издательство, 2006. - 341 с.

10. Суханова И.Ф., Лявина М.Ю., Заворотин Е.Ф. Инструменты политики импортозамещения продовольствия в России // Аграрный научный журнал. 2015. - № 8. - C. 96-100.

11. Тюрина Н.С., Маслова Е.Н. Оценка эффективности функционирования личных подсобных хозяйств Саратовской области // Вестник Саратовского госагроуниверситета им. Н.И. Вавилова. - 2009. - № 3. - С. 91-95.

12. Федеральная служба государственной регистрации, кадастра и картографии (Росреестр). - Режим доступа: https://rosreestr.ru/site/.

Заворотин Евгений Феофанович, $\partial-p$ экон. наук, проф., илен-корреспондент РАН, временно исполняюший обязанности директора, Поволжский научноисследовательский институт экономики и организации агропромышленного комплекса. Россия.

Гордополова Алла Александровна, канд. экон. наук, доцент, главный научный сотрудник, Поволжский научно-исследовательский институт экономики и организации агропромышленного комплекса. Россия.

Тюрина Наталья Сергеевна, канд. экон. наук, старший научный сотрудник, Поволжский научноисследовательский институт экономики и организации агропромышленного комплекса. Россия.

Потоцкая Людмила Николаевна, канд. экон. наук, доцент, старший научный сотрудник, Поволжский научно-исследовательский институт экономики и организации агропромышленного комплекса. Россия.

410010, г. Саратов, ул. Шехурдина, 12.

Тел.: (8452) 64-86-92; e-mail:nii_apk_sar@mail.ru.

Ключевые слова: модель; метод; эффективность; сельскохозяйственное землепользование; агроистощение; издержки; земельные отношения.

\section{MODEL OF INCREASING THE EFFICIENCY OF AGRICULTURAL LAND USE}

Zavorotin Evgeniy Pheophanovich, Doctor of Economic Sciences, Professor, Associate Member of RAS, Volga Research Institute of Economics and Organization of Agroindustrial Complex. Russia.

Gordopolova Alla Aleksandrovna, Candidate of Economic Sciences, Associate Professor, Chief Researcher, Volga Research Institute of Economics and Organization of Agroindustrial Complex. Russia.

Tiurina Nataliya Sergeevna, Candidate of Economic Sciences, Senior Researcher, Volga Research Institute of Economics and Organization of Agroindustrial Complex. Russia.

Pototskaya Lyudmila Nikolaevna, Candidate of Economic Sciences, Associate Professor, Senior Researcher, Volga Research Institute of Economics and Organization of Agroindustrial Complex. Russia.

Keywords: model; method; efficiency; agricultural land use; agrodepletion; costs; land relation.
A process model for regulating the interaction of the participants in land relations is proposed by ensuring the functioning of the method for increasing the efficiency of agricultural land use. The types of costs that have the greatest importance for increasing the efficiency of agricultural land use are identified. Method of minimization of land payments, pecuniary penalties, costs for agrotechnical measures for preserving, restoring the fertility of the soil, preventing their degradation and monocultural upbringing is considered. The specifics of payments by agricultural producers for damaging the environment, the possibility of compensating them for the costs of improving low-productivity land, are revealed. The complex of measures aimed at full or partial reimbursement by the state of costs for protecting the environment, a reallocation of the amounts of appropriate payments received to the budget for encouraging land users observing the norms of environmental safety is substantiated. A comparative assessment of the participants in land relations was made from the standpoint of effective and inefficient use of land in agriculture. 